\title{
FORMAÇÃO DE CONCEITOS, RECONHECIMENTO E MEMÓRIA VISUAL REDUZIDA EM CRIANÇAS E JOVENS COM PARALISIA CEREBRAL
}

DOI: $10.22289 / 2446-922 X . V 3 N 2 A 11$

\author{
Rodolfo Santos Flaborea \\ Elaine Cristina Zachi \\ Marcelo Fernandes Costa ${ }^{1}$
}

\section{RESUMO}

Nosso trabalho visa a avaliação de funções neuropsicológicas em crianças e jovens com paralisia cerebral. Foram avaliadas 23 crianças com paralisia cerebral do tipo espástica (PC) e 10 sujeitos saudáveis. Em duas sessões de avaliação, utilizamos uma bateria de testes neuropsicológicos para análise das funções de memória e reconhecimento visuais, reconhecimento espacial, memória operacional, planejamento de ações, flexibilidade mental e formação de conceitos, manutenção atencional, atenção visual sustentada e tempo de reação. Dos 23 sujeitos, apenas 10 apresentaram Q.I superior a 90 e foram comparados ao controle. Diferenças estatísticas foram encontradas para memória visual e reconhecimento, flexibilidade mental e formação de conceitos. As conclusões apresentadas são relacionadas à possíveis danos cerebrais e uma importante discussão metodológica é agregada ao texto.

Palavras-chave: paralisia cerebral; memória; atenção; funções corticais; neuropsicologia.

\section{ABSTRACT}

Our work aims at the evaluation of neuropsychological functions in children and young people with cerebral palsy. We evaluated 23 children with cerebral palsy spastic (PC) and 10 healthy subjects. In two evaluation sessions, we used a battery of neuropsychological tests to analyze the memory functions and visual recognition, spatial recognition, working memory, action planning, mental flexibility and concept formation, attentional maintenance, sustained visual attention and reaction time. Of the 23 subjects, only 10 had higher IQ at 90 and were compared to control. Statistical differences were found for visual recognition and memory, mental flexibility and concept formation. The conclusions presented are related to the possible brain damage and an important methodological discussion is aggregated to the text.

Keywords: cerebral palsy; memory; attention; cortical functions; neuropsychology.

\footnotetext{
${ }^{1}$ Endereço eletrônico de contato: costamf@usp.br Recebido em 24/09/2017. Aprovado pelo Conselho Editorial e aceito para publicação em 27/09/2017.
}

Rev. Psicol Saúde e Debate. Dez., 2017:3(2):131-158. 


\section{INTRODUÇÃO}

A Paralisia Cerebral (PC) é uma desordem muscular e do movimento que atinge bebês e crianças até 2 anos de idade, é ocasionada por lesões cerebral durante o desenvolvimento fetal, dentro do período perinatal ou ainda nos primeiros meses ou anos de vida (Straub \& Obrzut, 2009). Sua incidência, inclusive no Brasil, não está bem definida devido às dificuldades de se estabelecer exames diagnósticos uniformes, além do fato da doença não ter notificação compulsória (Cândido, 2004). Em países subdesenvolvidos, a incidência de todos os tipos de PC é de aproximadamente 7 para cada 1000 nascidos vivos (Cândido, 2004).

As etiologias dos insultos cerebrais podem variar consideravelmente, estendendo-se desde anomalias genéticas, uso de drogas pela mãe durante a gravidez até infecções cerebrais (como meningite bacteriana), anóxia neonatal e traumas encefálicos (Cândido, 2004). As naturezas das lesões também são bastante variáveis (Straub \& Obrzut, 2009), mas todas possuem um caráter não progressivo (Cândido, 2004). Análises por meio de Ressonância Magnética (MRI) (Bax et al., 2006) identificaram, em uma amostra de 585 crianças, danos na substância branca $(42,5 \%)$, nos gânglios da base $(12,8 \%)$, lesões corticais e subcorticais $(9,4 \%)$, más-formações $(9,1 \%)$, infartos focais $(7,4 \%)$ e lesões mistas $(7,1 \%)$. Apenas $11,7 \%$ da amostra tiveram resultados de MRI normais. Tal variabilidade na etiologia e nas lesões fornece ao grupo de indivíduos com paralisia cerebral um caráter heterogêneo (Straub \& Obrzut, 2009).

A literatura que abrange a análise neuropsicológica da paralisia cerebral é diversa devida à já mencionada variedade de natureza das lesões que acarretam em diferentes quadros clínicos (Straub \& Obrzut, 2009). Todavia, considerando a grande interferência de tal distúrbio na vida infantil, a literatura não é tão extensa como se esperaria, com os estudos se referindo, em sua maioria, apenas ao tipo espástico da PC (Straub \& Obrzut, 2009). Apesar disso, alguns aspectos neuropsicológicos podem ser considerados de maneira geral.

O funcionamento motor na paralisia cerebral pode ter mais ou menos prejuízos de acordo com a extensão da lesão cerebral. Os prejuízos foram encontrados tanto em funções motoras gerais (movimentos dos membros, por exemplo) como em funções motoras finas, (destreza manual) e variaram significativamente entre os subtipos de paralisia (Straub \& Obrzut, 2009).

Adicionalmente, um estudo (Himmelmann et al., 2006) expôs fortes correlações entre o nível das habilidades motoras gerais dos indivíduos com paralisia cerebral e a presença de déficits nas capacidades intelectuais. Todavia, uma pesquisa (van der Weel et al., 1996, apud

Rev. Psicol Saúde e Debate. Dez., 2017:3(2):131-158. 
Straub \& Obrzut, 2009) aponta a importância da análise conjunta das variáveis motoras e perceptuais visto que, segundo esse estudo, as informações sensoriais orientam os movimentos de determinadas partes do corpo. Assim, crianças com paralisia cerebral possuem uma maior dificuldade com tarefas motoras que não lhes fornecem dados perceptuais adequados.

A capacidade para o uso de habilidades linguísticas depende do nível dos prejuízos motores, cognitivos e sensoriais (Straub \& Obrzut, 2009). Uma pesquisa (Pirila et al., 2007) mostrou que pacientes com paralisia cerebral severa e cujos níveis de inteligência medidos foram baixos $(\mathrm{Q} \mid<70)$ demonstraram dificuldades não só no domínio motor da linguagem (fala) como também na compreensão e expressão verbais. Isso, segundo tal pesquisa, não foi igualmente observado em pacientes cujo QI estava acima de 70. Nestes foram observados prejuízos apenas na fala. Todavia, com relação às habilidades linguísticas básicas (habilidades fonológicas, fonêmicas, semânticas e léxicas), o desempenho de pacientes com paralisia cerebral mostrou-se comparável àquele do grupo controle em outra pesquisa (Sabbadini et al., 2001). Outro estudo mostrou também um funcionamento verbal melhor do que o não-verbal, ambos medidos por meio de testes de inteligência (Sabbadini et al., 2001; White \& Christ, 2005).

Nessa área de habilidades não-verbais, foram observados prejuízos nas habilidades visuo-perceptuais e visuo-espaciais (Sabbadini et al., 2001; Straub \& Obrzut, 2009). Um estudo (Wann, 1991) verificou que o funcionamento proprioceptivo em indivíduos com vários tipos de paralisia cerebral não sofreu melhoras devido a pistas fornecidas pelo sistema visual, melhora essa que ocorreu com os participantes saudáveis da pesquisa. O pesquisador responsável pelo estudo sugeriu que haveria um desvio visual sutil que ocasionaria um julgamento visuo-espacial prejudicado. Por outro lado, é também indicado que os adolescentes com distúrbio podem possuir dificuldades em processar informações entre os sistemas visual e proprioceptivo (Wann, 1991). Nesse caso, é possível que o cérebro de tais indivíduos apresente danos em estruturas responsáveis por executar tal função (Wann, 1991). Em outra análise (Sabbadini et al., 2001) observaram-se prejuízos em crianças com paralisia cerebral severa indicados pelos resultados em tarefas lógico-dedutivas visuo-espaciais.

Fedrizzi e colaboradores (1996) demonstraram uma forte correlação entre desempenho visuo-perceptual e alterações anatômicas características de PVL em crianças com PC nascidas prematuramente. Verificou-se uma grande discrepância entre o QI Verbal e o QI de Execução das escalas Wechsler (WPPSI e WISC-R, edições italianas) aplicadas nos participantes, com o QI de Execução significativamente abaixo da média, o que sugere prejuízos no funcionamento visuo-perceptivo (Fedrizzi et al., 1996). Tal resultado deste QI 
correlacionou-se fortemente aos danos de leucomalácia periventricular (severidade da dilatação ventricular, o grau de redução da substância branca, atrofia da radiação óptica e afinamento da porção posterior do corpo caloso) (Fedrizzi et al., 1996). A partir disso, postulou-se que os efeitos da PVL nos inputs sensoriais visuais podem ser considerados como um substrato neural para as deficiências observadas no domínio visuo-perceptual dos indivíduos com PC espástica. Adicionalmente outros estudos verificaram correlações entre os prejuízos visuo-perceptuais e outras áreas de funcionamento na paralisia cerebral. Dentre estas, tem-se dificuldades de leitura (Kozeis et al., 2006 apud Straub \& Obrzut, 2009) e de tarefas de reprodução gráfica de imagens (Courbois et al., 2004).

Em relação ao domínio da aprendizagem, foram observados prejuízos entre $40 \%$ (Himmelmann et al., 2006) e 44\% (Straub \& Obrzut, 2009) das amostras estudas. As causas de tais dificuldades podem ser encontradas em déficits na memória operacional e em funções executivas, como visto em algumas pesquisas (Dahlgren-Sandberg, 2006; Schatz et al., 1997; White \& Christ, 2005). Em uma delas (Dahlgren-Sandberg, 2006), foi realizado um estudo longitudinal para avaliar o desenvolvimento da capacidade de leitura e escrita em um grupo de crianças com PC que possuíam um QI normal. A essa capacidade foram relacionados desenvolvimento intelectual (QI, medido pelo Teste Matrizes Progressivas Coloridas de Raven), habilidades fonológicas (identificação de sons, reconhecimento de rimas, análise do tamanho de palavras, entre outros) e memória operacional (Dígitos do WISC, memória auditiva e visuo-espacial, entre outros) (Dahlgren-Sandberg, 2006). Os resultados mostraram que os participantes com PC tiveram dificuldades em desenvolver habilidades de leitura, fala e nomeação, ainda que o nível normal inicial de inteligência e os ganhos observados na área fonológica tenham indicado o contrário. Tal prejuízo na aprendizagem, como sugeridos pelos pesquisadores, pode ter sido decorrente dos déficits encontrados na memória operacional, sendo necessárias, segundo o estudo, mais análises sobre o papel desta modalidade de memória e da alça fonológica na aquisição das habilidades de leitura e escrita.

Em outra pesquisa (White \& Christ, 2005), foi visto que crianças com PC espástica tiveram mais dificuldades no domínio executivo (categorização espontânea e categorização auxiliada por pistas) do que naquele caracteristicamente associativo (aprendizagem inicial e retenção de informação ao longo do tempo) em tarefas de memorização de palavras (White \& Christ, 2005). Esta última mostrou-se preservada de acordo com os resultados dos testes. Os autores concluíram que as áreas mediais temporais do cérebro, que processam o aprendizado associativo, estavam relativamente preservadas (White \& Christ, 2005), e que as lesões cerebrais relacionadas à $\mathrm{PC}$ atingiram as áreas pré-frontais do cérebro, o que prejudica o funcionamento dos aspectos executivos do aprendizado. Outro estudo (Schatz et al., 1997) 
pôde verificar, adicionalmente, a existência de prejuízos na aprendizagem de pares associados que exigiram respostas não-verbais dos participantes com PC espástica diplégica. Foi observada uma relação entre tal dificuldade e a severidade da lesão cerebral, analisada por meio de MRI (Schatz et al., 1997). Os pesquisadores responsáveis sugeriram que danos na substância branca (sejam eles difusos ou circunscritos a determinados locais do cérebro), ocasionados por PVL, podem interferir no processamento de aprendizagem não-verbal (Schatz et al., 1997). Esse resultado contribui para a conclusão geral de que, em crianças com paralisia cerebral, as habilidades não-verbais tendem a estar menos desenvolvidas que as habilidades verbais (Straub \& Obrzut, 2009).

Os danos à substancia branca observados no cérebro de pacientes com paralisia cerebral possibilitam a elaboração da hipótese de que as funções executivas podem estar prejudicadas (Christ et al., 2003). Isso decorre do fato de que o funcionamento executivo depende não só da atividade dos lobos pré-frontais, mas também das conexões entre estes e demais áreas do cérebro, ligações essas estabelecidas pelas fibras da substância branca (Christ et al., 2003). Em relação a essa hipótese, foram observadas evidências de prejuízos no controle inibitório de crianças com PC bilateral espástica (Christ et al., 2003). Tal variável foi analisada a partir do tempo de reação e da quantidade de erros, ambos obtidos por meio dos resultados dos participantes no teste de Stroop, em uma tarefa de estímulo-resposta e em uma tarefa antissacádica. Outra pesquisa, descrita acima, (White \& Christ, 2005) indicou prejuízos nos aspectos executivos do aprendizado. Adicionalmente, resultados obtidos em outros estudos apóiam a hipótese da existência de prejuízos no funcionamento executivo, com déficits observados em atenção visual e auditiva, planejamento, tempo de reação e inibição (Straub \& Obrzut, 2009).

Os resultados das pesquisas, em suma, permitem constatar que existem diversos prejuízos cognitivos associados à paralisia cerebral. Correlações entre os quadros cognitivos e os tipos de lesões cerebrais ainda não foram claramente estabelecidas, apesar de alguns estudos já terem observado importantes relações (Fedrizzi et al 1996.; Lidzba et al., 2006; Schatz et al., 1997).

Assim, a presente pesquisa tem como objetivo estudar o funcionamento das diversas funções neuropsicológicas em crianças e jovens com paralisia cerebral. A relevância deste estudo não só se aplica ao conhecimento do impacto das lesões neurais no funcionamento do sistema nervoso, bem como pode oferecer material para o planejamento de estratégias de reabilitação mais dirigidas e, portanto, com maior chances de sucesso.

Rev. Psicol Saúde e Debate. Dez., 2017:3(2):131-158. 


\section{Materiais e Métodos}

Foram avaliados os desempenhos de dois grupos, um composto por 23 sujeitos com paralisia cerebral espástica, e outro composto por 10 sujeitos saudáveis usados como controle (tabela 1). Os sujeitos com PC foram encaminhados pela Prof ${ }^{-} \mathrm{Dr}^{\mathrm{a}}$ Renata Hydee Hasue Vilibor do Departamento de Fisioterapia, Fonoaudiologia e Terapia Ocupacional da Faculdade de Medicina da USP (FMUSP). A presente pesquisa foi aprovada pelo Comitê de Ética em Pesquisas com Seres Humanos da USP (CEPH-IPUSP), sob o parecer ํㅜ 2009065.

Tabela 1

Dados demográficos de todos os participantes da pesquisa. Os resultados de QI foram obtidos a partir da conversão dos escores do Teste das Matrizes Progressivas e do Teste das Matrizes Coloridas segundo Spreen e colaboradores, 2006.

\begin{tabular}{cccccc|ccccc}
\hline & \multicolumn{9}{c}{ Paralisia Cerebral } & \multicolumn{4}{c}{ Controles } \\
\cline { 2 - 10 } & $\begin{array}{c}\mathbf{n} \\
\text { válido }\end{array}$ & Média & Mínimo & Máximo & $\begin{array}{c}\text { Desvio } \\
\text { Padrão }\end{array}$ & $\begin{array}{c}\mathbf{n} \\
\text { válido }\end{array}$ & $\begin{array}{c}\text { Médi } \\
\text { a }\end{array}$ & Mínimo & Máximo & $\begin{array}{c}\text { Desvio } \\
\text { Padrão }\end{array}$ \\
\hline Idade & 23 & 10,2609 & 5,0 & 16,0 & 3,20819 & 10 & 7,30 & 6,0 & 11,0 & 1,8886 \\
Escolaridade & 21 & 4,04762 & 0,0 & 9,0 & 2,65474 & 10 & 2,10 & 1,0 & 5,0 & 1,5238 \\
QI & 19 & 92,0526 & 67,0 & 124,0 & 17,55459 & 10 & 116,0 & 92,0 & 129,0 & 10,863 \\
\hline
\end{tabular}

Cada participante com PC foi submetido a duas sessões de avaliação neuropsicológica, cada uma com aproximadamente uma hora de duração, realizada no Instituto de Psicologia da USP. Iniciou-se a sessão de avaliação neuropsicológica com uma breve coleta de dados demográficos (idade e escolaridade) e, em seguida, houve a aplicação dos testes neuropsicológicos. Os testes utilizados nas sessões foram o Teste Matrizes Progressivas de Raven, o Teste Matrizes Progressivas Coloridas de Raven e os Subtestes da Bateria Neuropsicológica Computadorizada Cambridge.

O Teste Matrizes Progressivas de Raven - Escala Geral (Campos, 2004) é formado por 60 problemas divididos em 5 séries, A, B, C, D e E, cada qual composta por 12 matrizes. As matrizes incluem 9 figuras impressas. Em cada matriz, falta uma das figuras para que 0 examinando selecione, dentre 8 possibilidades, aquela que completa a matriz formando uma seqüência lógica (Figura 1).

Rev. Psicol Saúde e Debate. Dez., 2017:3(2):131-158. 


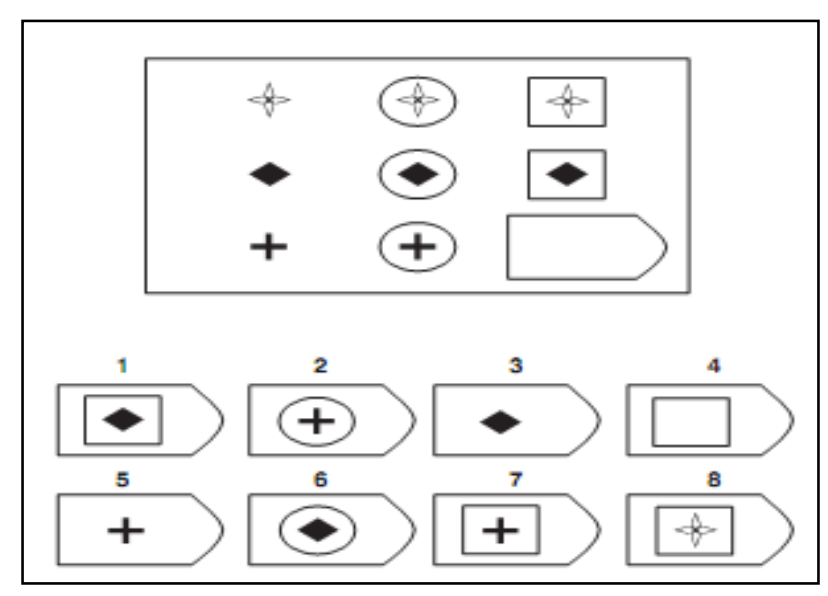

Figura 1: Item do Teste Matrizes Progressivas de Raven. Fonte: Costa, Azambuja, Portuguez \& Costa, 2004

O Teste Matrizes Progressivas Coloridas de Raven (Angelini, Alves, Custódio, Duarte, \& Duarte, 1999) é formado por 36 problemas, semelhantes aos da Escala Geral, divididos em 3 séries, $A, A B$ e $B$ cada qual composta por 12 matrizes e o indivíduo tem de escolher a resposta correta dentre 6 possibilidades.

Subtestes da Bateria Neuropsicológica Computadorizada Cambridge Neuropsychological Test Automated Battery (CANTABeclipse versão 3.0) (Cambridge Cognition, 2005), como descritos abaixo:

- $\quad$ PRM (Pattern Recognition Memory): Teste que avalia a memória visual e reconhecimento. Este teste apresenta-se em duas etapas. A primeira consiste na apresentação de uma série contendo 12 padrões visuais (um por vez) no centro da tela do computador. Em seguida são apresentados dois estímulos concomitantemente, um já visto anteriormente pelo sujeito e outro desconhecido, como mostrado na figura 2. Cabe ao sujeito reconhecer entre esses dois estímulos aquele que já lhe foi apresentado (recuperação imediata). A Segunda fase é igual à primeira, porém a fase de reconhecimento só é apresentada após 20 minutos, ou seja, somente após 20 minutos e que serão apresentados dois estímulos concomitantemente, um já visto anteriormente pelo sujeito e outro desconhecido. Cabe ao sujeito reconhecer entre esses dois estímulos aquele que já the foi apresentado (recuperação tardia). 


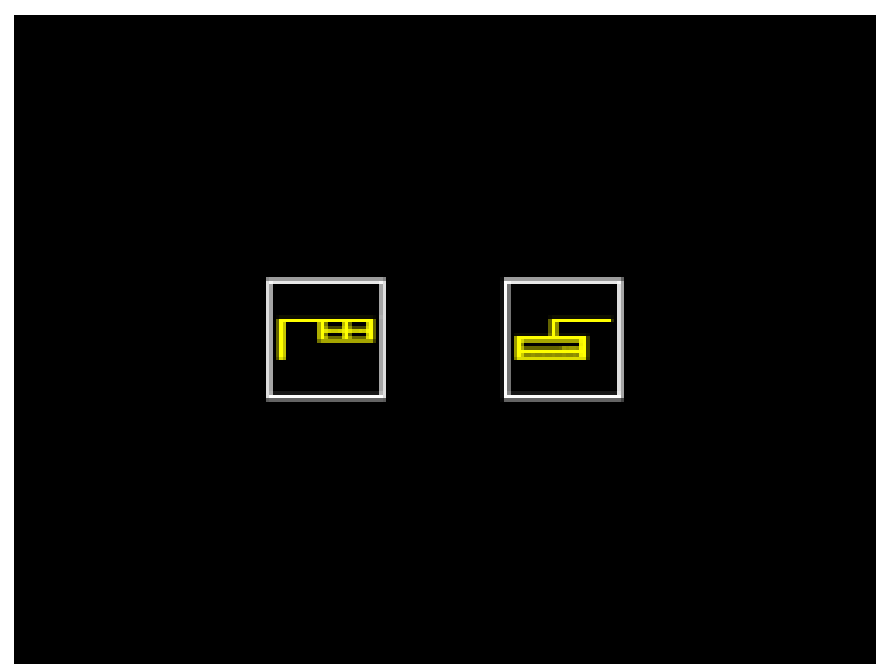

Figura 11: fase de reconhecimento do subteste Pattern Recognition Memory. Fonte: Cambridge Cognition, 2005.

- $\quad$ SRM (Spatial Recognition Memory): É um teste de reconhecimento espacial com um total de 25 apresentações de estímulos (quadrados) divididas em cinco blocos de 5 apresentações. As apresentações são feitas seqüencialmente, uma de cada vez, em 5 posições diferentes na tela do computador. Após as cinco apresentações aparecem dois quadrados simultaneamente, em posições diferentes sendo que somente um deles está na exata posição de um dos estímulos apresentados anteriormente. O sujeito deve reconhecer a posição correta dos quadrados, como é exposto na figura 3.

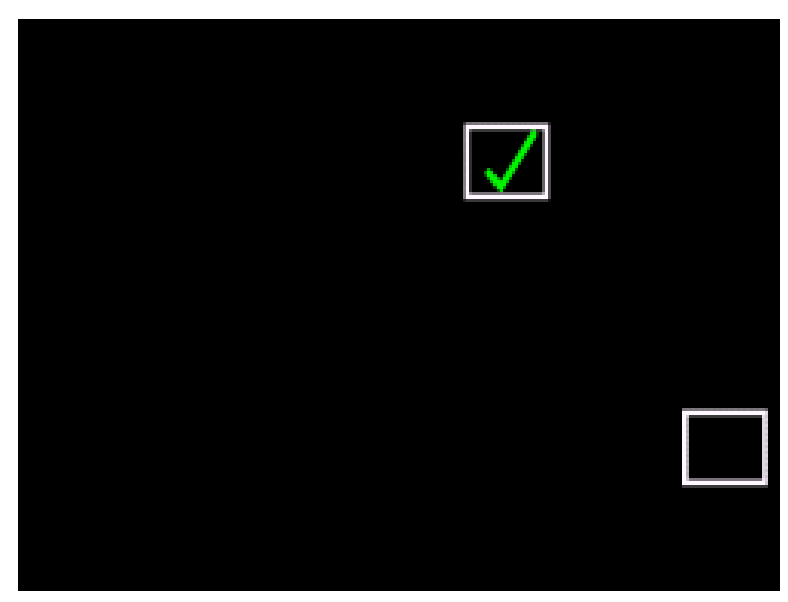

Figura 12: Fase de reconhecimento do subteste Spatial Recognition Memory. Fonte: Cambridge Cognition, 2005.

Rev. Psicol Saúde e Debate. Dez., 2017:3(2):131-158. 
- $\quad \operatorname{SSP}$ (Spatial Span): Este teste avalia memória operacional e possui duas fases. São apresentados 9 quadrados brancos que ficam fixos na tela do computador. Alguns destes quadrados ficam brevemente coloridos em uma determinada ordem, tal como a figura 4 mostra. Na primeira fase o sujeito deve indicar quais dos quadrados ficaram coloridos exatamente na mesma ordem em que eles mudaram de cor e na segunda fase isso deve ocorrer na ordem invertida, ou seja, de traz para frente. Começa-se o teste com dois quadrados que acendem e terminando com nove. A cada acerto o número de quadrados que ficam coloridos aumenta. O teste é interrompido após uma terceira tentativa errada num mesmo número de quadrados.

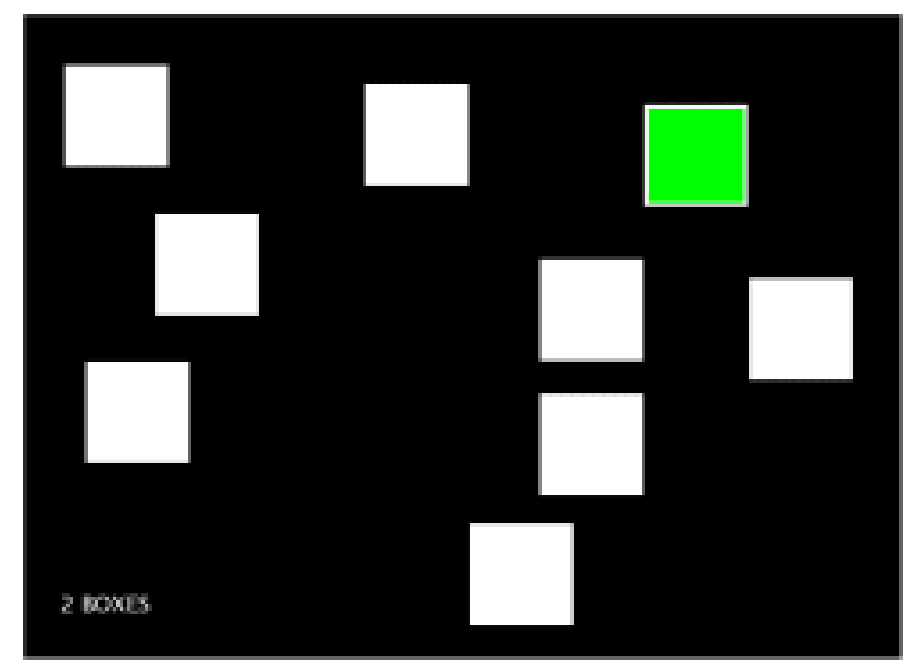

Figura 13: configuração visual no subteste Spatial Span, com um quadrado aceso. Fonte:

Cambridge Cognition, 2005.

- SOC (Stockings of Cambridge): Esse teste avalia planejamento de ações, formações de conceitos (funções executivas) e memória operacional. Na tela são apresentados 2 arranjos contendo 3 bolas coloridas (vermelha, verde e azul) (figura 5). O arranjo localizado na parte superior da tela (modelo) deve ser reproduzido pelo sujeito na parte inferior, com o menor número de movimentos possíveis. Na fase inicial do teste são requeridos até 4 movimentos para reproduzir o arranjo e na fase seguinte são requeridos até cinco movimentos. Existem ainda duas outras fases, uma depois da primeira fase e outra depois da segunda fase de reprodução do modelo, nas quais o computador reproduz os movimentos executados pelo participante na 
fase anterior e este terá apenas que "seguir" o movimento efetuado pelo computador. Esta fase serve para medir o tempo de raciocínio do sujeito durante a movimentação das bolas ao subtrair o tempo que o sujeito leva para simplesmente movimentar as bolas numa situação de cópia do tempo total que ele levou para resolver o problema na fase anterior.

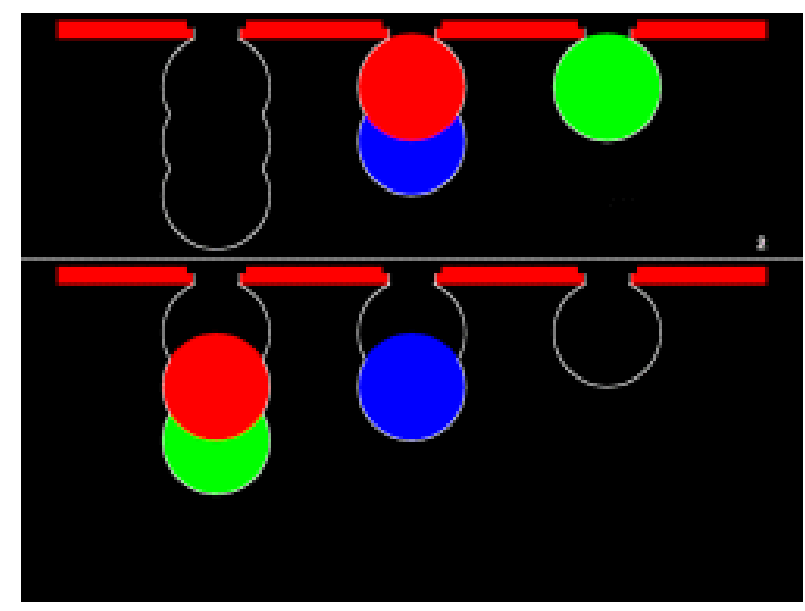

Figura 14: configuração visual do subteste Stockings of Cambridge. Fonte: Cambridge Cognition, 2005.

- $\quad$ IED (Intra-Extra Dimensional Set Shift): Teste composto por nove estágios que avaliam a flexibilidade mental e formação de conceitos (funções executivas) além da manutenção atencional. Nas duas primeiras partes, o estímulo é composto por duas formas coloridas e, nos estágios seguintes, são acrescidas linhas brancas a esses estímulos coloridos (figura 6). A tarefa do sujeito é indicar qual a figura correta, que ele aprende através de feedback fornecido pelo teste após cada tentativa. A cada 6 respostas corretas, a regra é modificada. Até o estágio 7 somente os estímulos coloridos são considerados corretos e, nos estágios 8 e 9 (fase extra-dimensional), os estímulos brancos. 


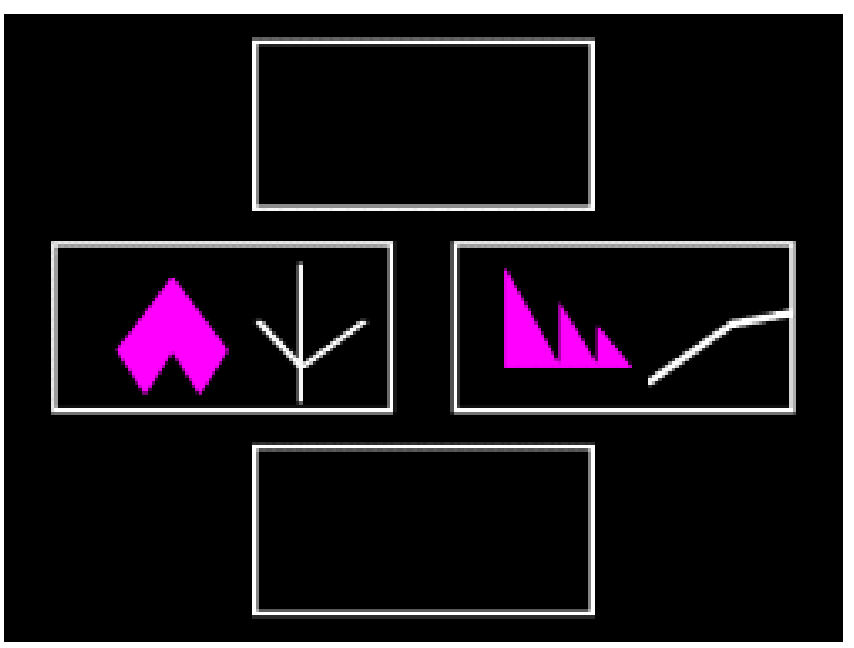

Figura 15: configuração visual do subteste Intra-extra Dimensional Set Shift. Fonte: Cambridge Cognition, 2005.

- RVP (Rapid Information Processing): Esse teste avalia atenção visual sustentada. No centro da tela aparece um quadrado com dígitos, de 2 a 9, que mudam até 100 vezes por minuto em seqüência aleatória (figura 7). O sujeito deve pressionar o botão de uma caixa de respostas imediatamente após cada ocorrência da sequência 3-5-7 (idade maior que 7 anos) ou 1-2-3 (idade menor que 7 anos) que aparece num total de 24 vezes.

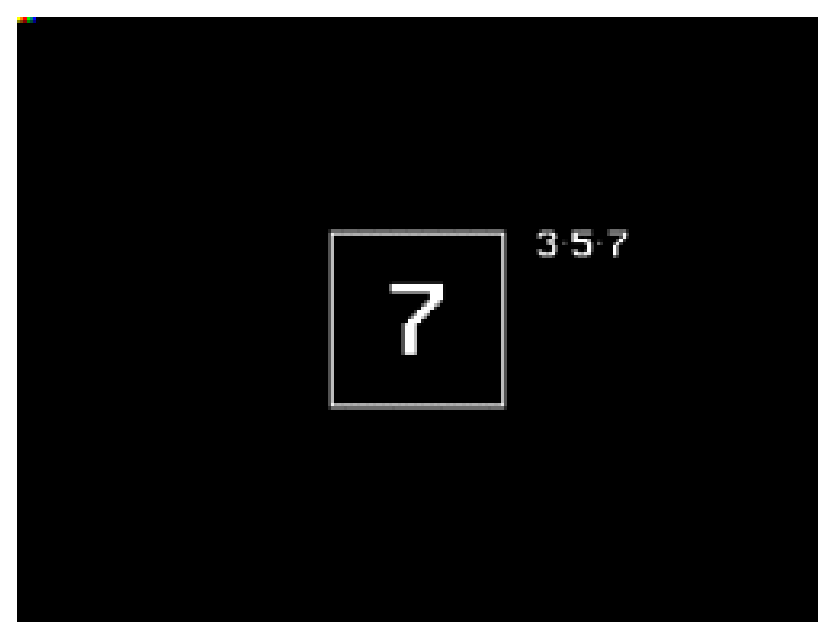

Figura 16: Caixa com dígitos do subteste Rapid Information Processing. Na parte superior direita do quadrado aparece a sequência à qual o sujeito deve responder. Fonte: Cambridge Cognition, 2005. 
- $\quad$ CRT (Choice Reaction Time): é um teste que mede o tempo de reação numa situação de escolha. Na tela é mostrada uma seta que pode aparecer apontada para a esquerda ou para a direita. O sujeito deve pressionar um dos dois botões de uma caixa de respostas de acordo com o local para onde a seta aponta: se ela apontar para a esquerda, o botão esquerdo deve ser pressionado, se ela apontar para o lado direito, deve-se pressionar o botão direito. Há, primeiramente, uma fase de treinamento (bloco 1), que possui 24 tentativas, e duas fases de avaliação propriamente dita (bloco 2 e bloco 3), as quais são constituídas, cada uma, por 50 tentativas.

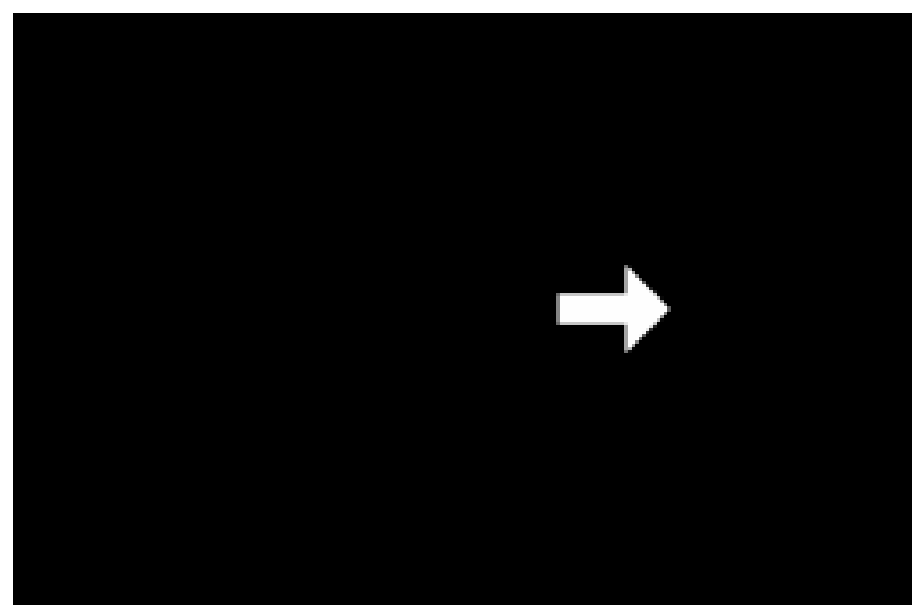

Figura 17: Configuração visual do teste Choice Reaction Time. A seta pode apontar tanto para a direita (como ilustrado) como para a esquerda. Fonte: Cambridge Cognition, 2005.

Os resultados dos indivíduos do grupo controle foram coletados em banco de dados formado por resultados de estudos prévios. A comparação do desempenho entre as duas amostras foi realizada, pareando-se idade e escolaridade, mediante estatística paramétrica (ANOVA). Tal procedimento estatístico foi utilizado conforme a distribuição dos resultados, que se revelou normal de acordo com o teste de Kolmogorov-Smirnov. O parâmetro de significância considerado foi de $p \leq 0,05$. Para as análises dos resultados foi utilizado 0 programa Statistica, 9.0 de StatSoft, Inc., EUA.

Os critérios de inclusão dos sujeitos com PC na comparação com os controles foram: Diagnóstico de Paralisia Cerebral; Valor de QI maior que 90. Os critérios de exclusão foram: 
Presença de limitações motoras severas; Presença de distúrbios da visão que pudesse impedir uma avaliação adequada e, portanto, a obtenção de escores fidedignos.

\section{RESULTADOS}

Dos 23 sujeitos, apenas 10 entraram na análise comparativa já que tiveram valores de QI maiores que 90, além de não terem apresentado distúrbios motores severos nem distúrbios visuais.

A tabela 2 expõe as médias e os desvios-padrão de todos os resultados obtidos com a aplicação da bateria CANTAB tanto para o grupo de sujeitos de controle como para o de sujeitos com paralisia cerebral. A significância ( $p$ ) obtida pela análise estatística com o teste ANOVA revelou diferenças entre as duas amostras quanto às variáveis dos subtestes PRM (Pattern Recognition Memory), SRM (Spatial Recogntion Memory) e IED (Intra-Extra Dimensional Set Shift).

Tabela 2

Tabela com os resultados dos controles em todos os subtestes da bateria neuropsicológica CANTAB.

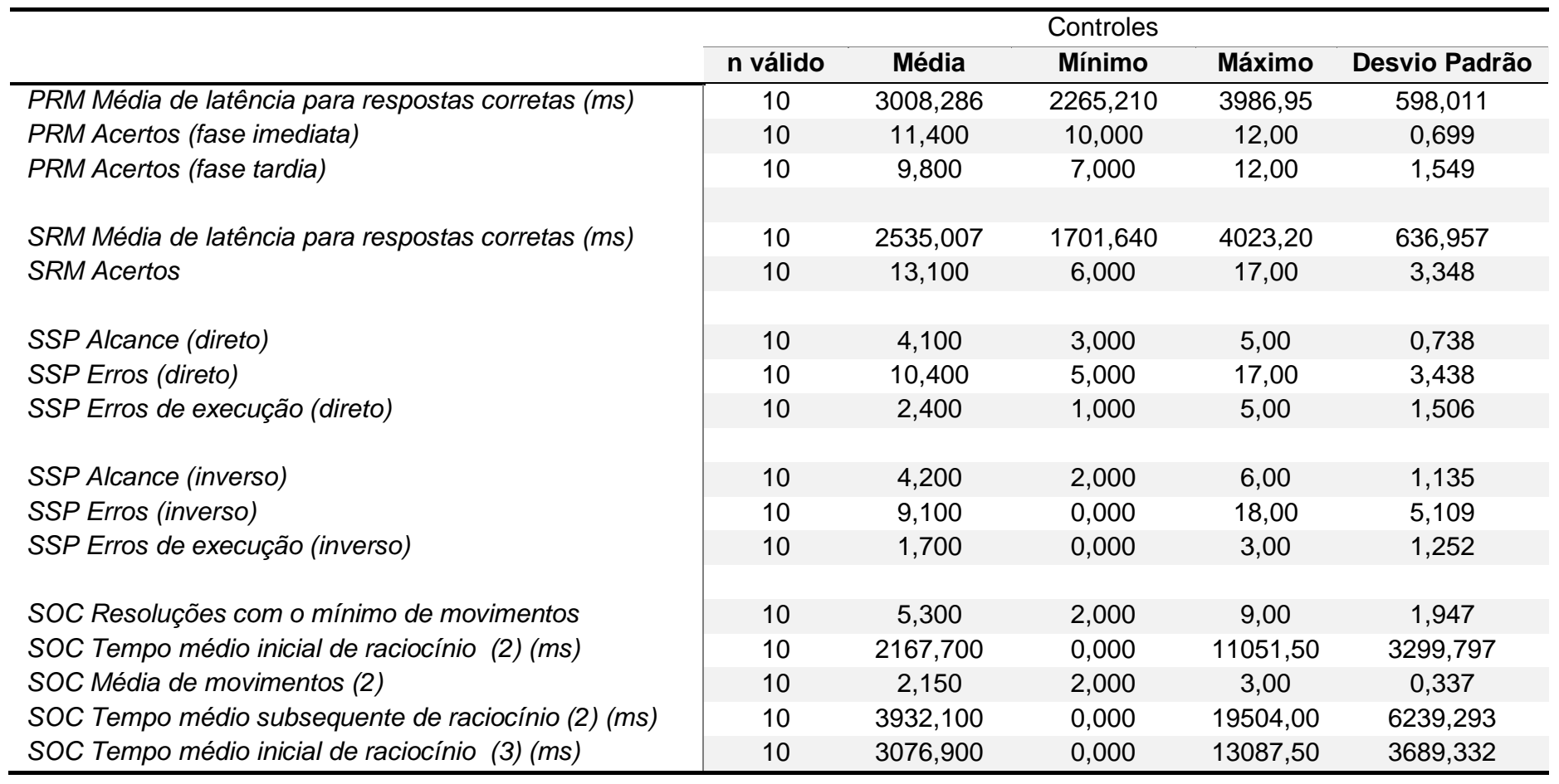

Rev. Psicol Saúde e Debate. Dez., 2017:3(2):131-158. 


\begin{tabular}{|c|c|c|c|c|c|}
\hline & \multicolumn{5}{|c|}{ Controles } \\
\hline & $\mathrm{n}$ válido & Média & Mínimo & Máximo & Desvio Padrão \\
\hline SOC Média de movimentos (3) & 10 & 4,400 & 3,000 & 5,50 & 0,966 \\
\hline SOC Tempo médio subsequente de raciocínio (3) ( $m s$ ) & 10 & 3333,142 & 0,000 & 14202,40 & 4480,942 \\
\hline SOC Tempo médio inicial de raciocínio (4) (ms) & 10 & 4556,975 & 250,250 & 23325,00 & 7013,968 \\
\hline SOC Média de movimentos (4) & 10 & 6,025 & 4,250 & 7,00 & 0,854 \\
\hline SOC Tempo médio subsequente de raciocínio (4) ( $m s$ ) & 10 & 6417,796 & 601,520 & 24343,90 & 6795,311 \\
\hline SOC Tempo médio inicial de raciocínio (5) (ms) & 10 & 1983,050 & 0,000 & 12813,25 & 3894,899 \\
\hline SOC Média de movimentos (5) & 10 & 8,850 & 5,250 & 10,50 & 1,524 \\
\hline SOC Tempo médio subsequente de raciocínio (5) (ms) & 10 & 3524,221 & 0,000 & 7670,10 & 3040,598 \\
\hline IED Erros em estágios completos & 10 & 15,700 & 5,000 & 34,00 & 11,700 \\
\hline IED Tentativas em estágios completos & 10 & 76,000 & 47,000 & 132,00 & 28,538 \\
\hline IED Erros EDS & 10 & 24,600 & 14,000 & 32,00 & 6,328 \\
\hline IED Erros Pré-ED & 10 & 9,800 & 5,000 & 20,00 & 5,308 \\
\hline IED Estágios completos & 10 & 7,400 & 7,000 & 9,00 & 0,699 \\
\hline IED Erros & 10 & 41,100 & 29,000 & 65,00 & 11,609 \\
\hline IED Erros (ajustado) & 10 & 58,600 & 33,000 & 69,00 & 10,490 \\
\hline IED Tentativas & 10 & 121,000 & 97,000 & 156,00 & 21,029 \\
\hline IED Tentativas (ajustado) & 10 & 156,000 & 132,000 & 184,00 & 15,741 \\
\hline CRT Latência máxima (tentativas corretas) (ms) & 10 & 1620,500 & 663,000 & 3099,00 & 772,871 \\
\hline CRT Média de latência (tentativas corretas) (ms) & 10 & 599,288 & 417,770 & 1088,64 & 223,814 \\
\hline CRT Latência mínima (tentativas corretas) (ms) & 10 & 272,400 & 150,000 & 442,00 & 80,028 \\
\hline CRT Erros (antencipação) & 10 & 2,500 & 0,000 & 22,00 & 6,868 \\
\hline CRT Tentativas corretas & 10 & 91,000 & 69,000 & 99,00 & 8,589 \\
\hline CRT Tentativas incorretas & 10 & 6,200 & 1,000 & 12,00 & 3,765 \\
\hline CRT Erros (omissão) & 10 & 0,300 & 0,000 & 2,00 & 0,675 \\
\hline$R V P A^{\prime}$ & 9 & 0,946 & 0,890 & 0,99 & 0,036 \\
\hline$R V P B^{\prime \prime}$ & 9 & 0,758 & 0,440 & 1,00 & 0,180 \\
\hline RVP Latência média (ms) & 10 & 405,861 & 266,570 & 680,00 & 124,894 \\
\hline RVP Probabilidade de alarme falso & 9 & 0,027 & 0,000 & 0,09 & 0,031 \\
\hline RVP Probabilidade de acerto & 9 & 0,818 & 0,670 & 0,96 & 0,101 \\
\hline RVP Rejeições corretas & 10 & 258,300 & 237,000 & 272,00 & 12,667 \\
\hline RVP Alarmes falsos & 9 & 6,556 & 0,000 & 23,00 & 7,923 \\
\hline RVP Acertos & 10 & 19,200 & 16,000 & 23,00 & 2,530 \\
\hline RVP Erros & 9 & 4,444 & 1,000 & 8,00 & 2,404 \\
\hline
\end{tabular}

No teste SSP, a variável "Alcance" se refere à maior sequência recordada pelo sujeito. No teste IED, "Erros EDS" se refere aos erros cometidos na fase extra-dimensional e "Erros Pré-ED", aos erros cometidos antes dessa fase. No teste RVP, A' é uma medida, segundo a Teoria de Detecção de Sinal (SDT) da sensibilidade do sujeito ao alvo, independentemente de sua tendência para resposta. B" se refere à tendência de resposta do sujeito independentemente do aparecimento ou não da sequênciaalvo, também segundo os princípios da (SDT) (Cambridge Cognition, 2005). 
Tabela 3

\section{Tabela com os resultados dos sujeitos com PC em todos os subtestes da bateria} neuropsicológica CANTAB e os valores de significância estatística (p).

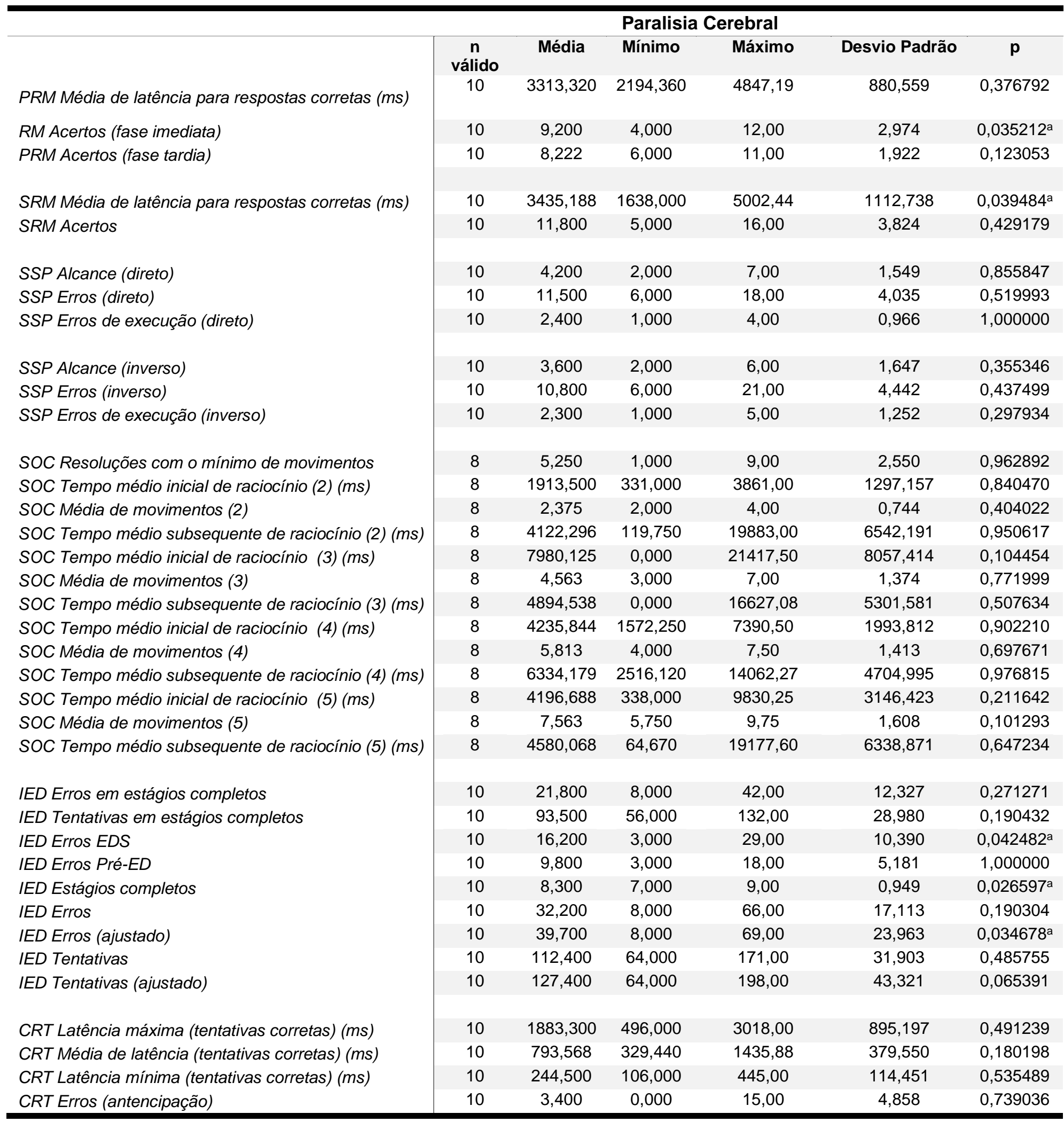

Rev. Psicol Saúde e Debate. Dez., 2017:3(2):131-158. 


\begin{tabular}{lcccccc}
\hline & & & & Paralisia Cerebral & p \\
\cline { 2 - 7 } & $\mathrm{n}$ válido & Média & Mínimo & Máximo & Desvio Padrão \\
\hline CRT Tentativas corretas & 10 & 88,500 & 72,000 & 99,00 & 11,597 & 0,590561 \\
CRT Tentativas incorretas & 10 & 6,200 & 1,000 & 15,00 & 5,653 & 1,000000 \\
CRT Erros (omissão) & 10 & 1,900 & 0,000 & 8,00 & 2,885 & 0,104869 \\
& & & & & & \\
RVP A' & 9 & 0,923 & 0,830 & 1,00 & 0,059 & 0,346689 \\
RVP B" & 9 & 0,464 & $-1,000$ & 0,85 & 0,571 & 0,161228 \\
RVP Latência média (ms) & 9 & 503,066 & 279,050 & 1088,57 & 245,553 & 0,284411 \\
RVP Probabilidade de alarme falso & 9 & 0,040 & 0,010 & 0,14 & 0,044 & 0,466485 \\
RVP Probabilidade de acerto & 9 & 0,767 & 0,580 & 1,00 & 0,157 & 0,422494 \\
RVP Rejeições corretas & 9 & 251,222 & 206,000 & 273,00 & 20,849 & 0,377939 \\
RVP Alarmes falsos & 9 & 10,556 & 3,000 & 34,00 & 10,454 & 0,373856 \\
RVP Acertos & 9 & 18,333 & 14,000 & 24,00 & 3,808 & 0,562779 \\
RVP Erros & 9 & 5,556 & 0,000 & 10,00 & 3,678 & 0,459097 \\
\hline
\end{tabular}

a Se referem aos valores significativos de $p$, segundo o teste ANOVA $(p<0,005)$.

No PRM, os indivíduos com paralisia cerebral acertaram menos vezes na etapa do teste na qual Ihes fora exigida a recuperação imediata dos estímulos anteriormente apresentados (Figura 9). Adicionalmente, esses mesmos sujeitos levaram um maior tempo para responder corretamente no teste SRM (Figura 10).

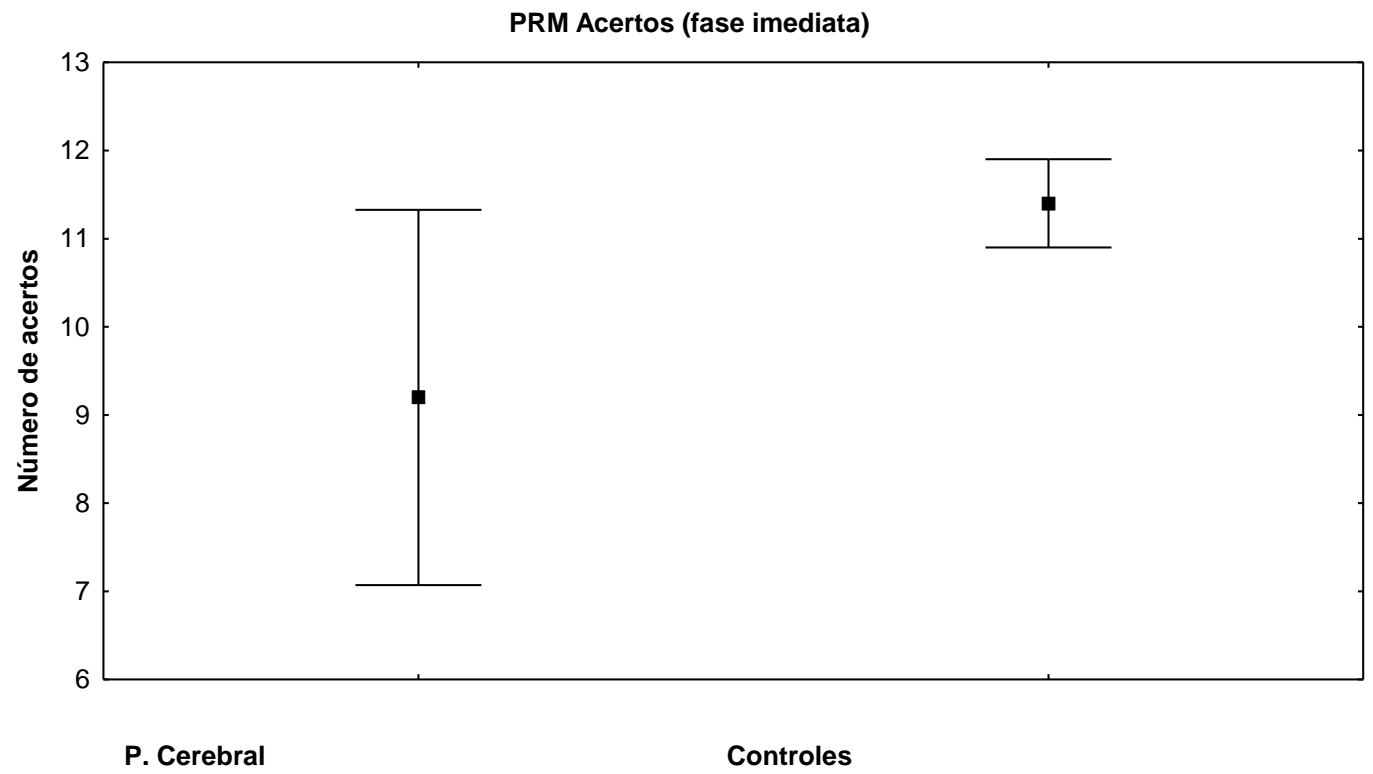

Figura 9: Número de acertos para as crianças com PC e controles.

Rev. Psicol Saúde e Debate. Dez., 2017:3(2):131-158. 


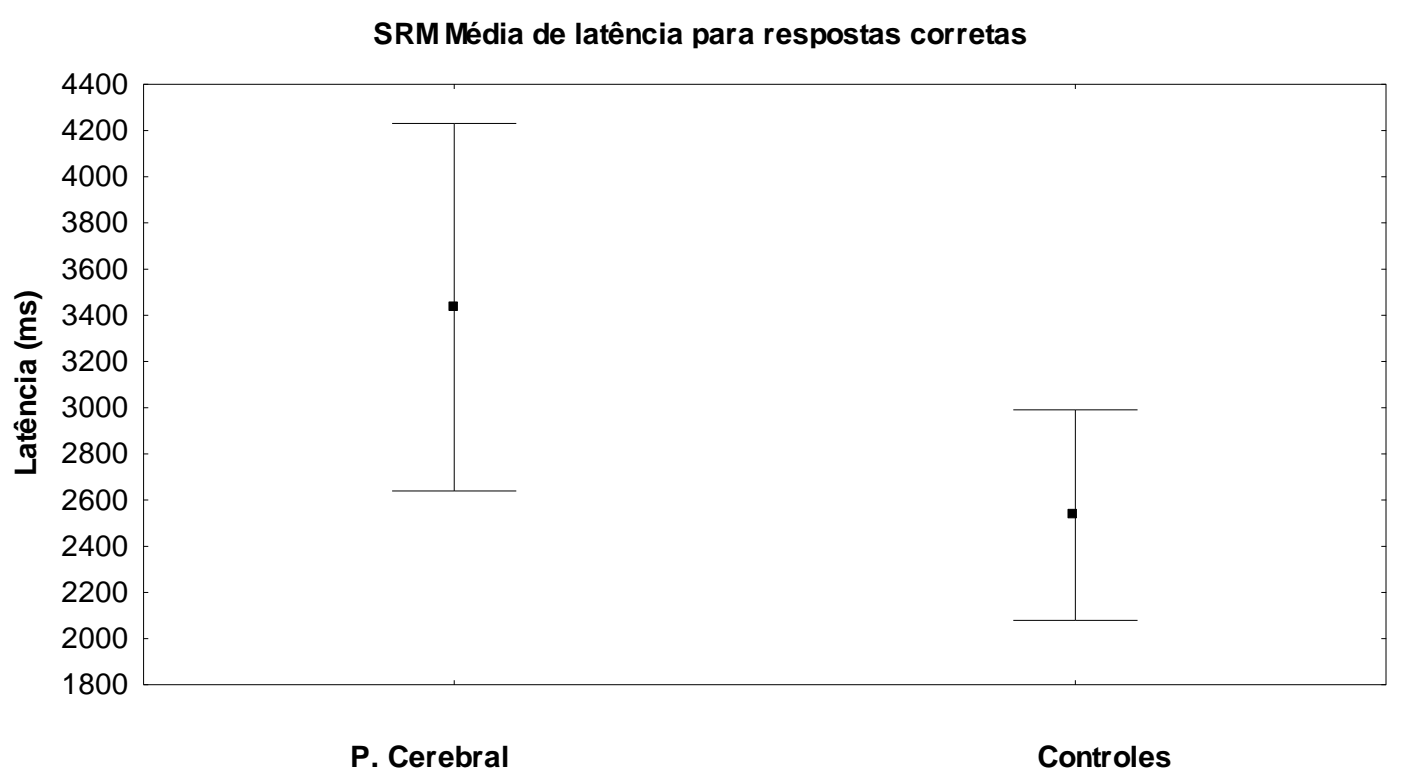

Figura 10: Latência de respostas das crianças com PC e controles.

Já em relação ao IED, os sujeitos com PC fizeram menos erros no estágio do teste em que Ihes fora pedido para realizarem uma mudança extra-dimensional, isto é, mudar seu foco de atenção para as formas anteriormente irrelevantes (linhas brancas) e aprender qual dentre esses dois exemplares de estímulo era o correto naquele momento (Figura 11). Além disso, tais sujeitos completaram um maior número de estágios do teste e cometeram menos erros ao longo deste (Figura 12 e Figura 13, respectivamente).

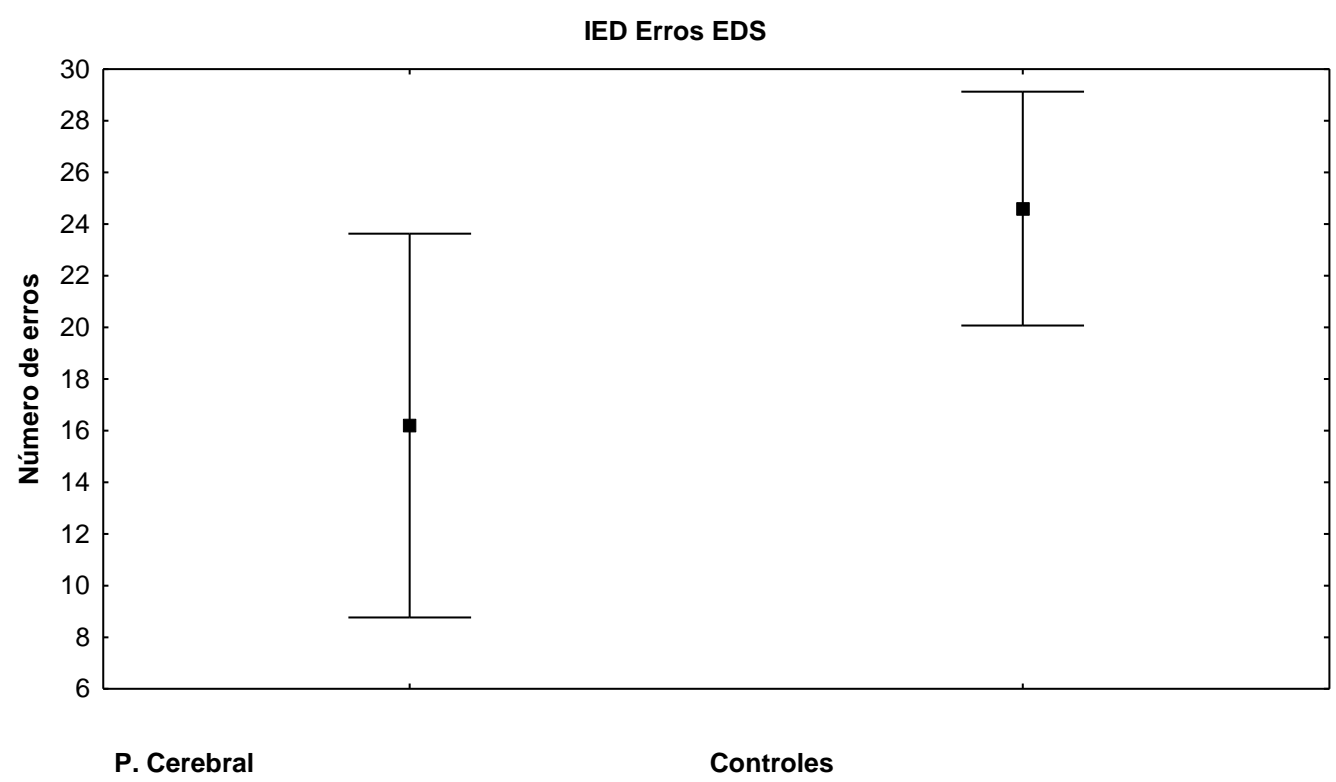

Figura 118: Quantidade de erros na fase extra-dimensional para crianças com PC e controles.

Rev. Psicol Saúde e Debate. Dez., 2017:3(2):131-158. 
IED Estágios completos

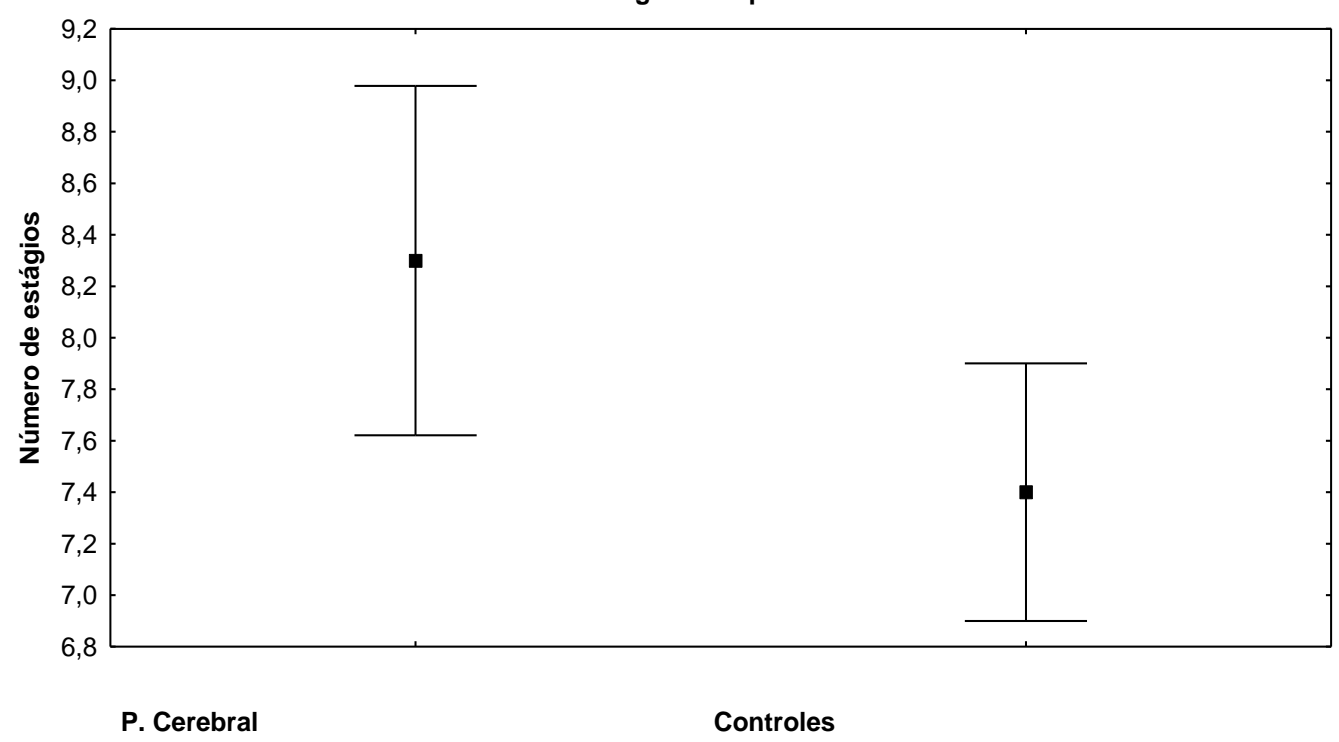

Figura 12: Número de estágios completos no teste IED para crianças com PC e controles.

IED Erros (ajustado)

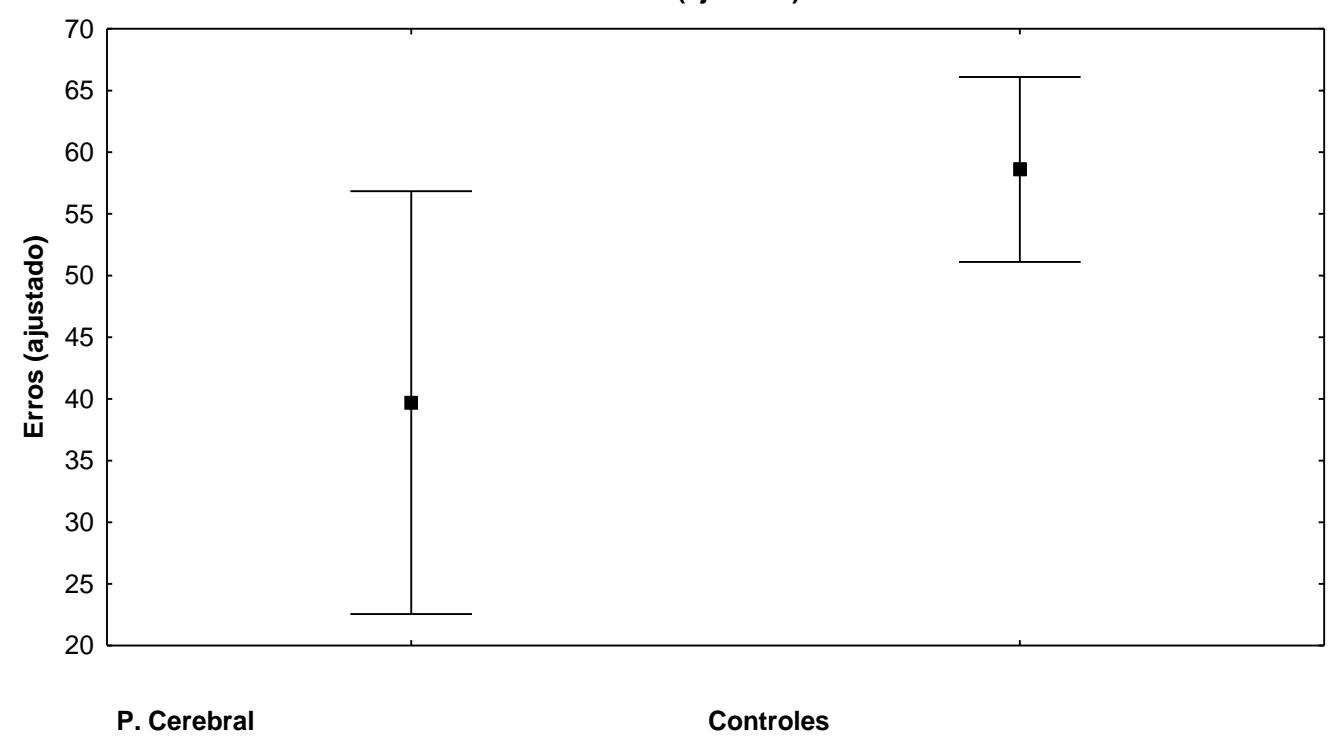

Figura 13: Número de erros ajustado para crianças com PC e controles. Quanto mais o sujeito avança no teste, maior é a probabilidade de errar do que outros que avancem menos no teste. Assim, o número de erros é ajustado de acordo com o desempenho do indivíduo, adicionando-se 25 a cada estágio não alcançado.

Rev. Psicol Saúde e Debate. Dez., 2017:3(2):131-158. 
Já a tabela 4 apresenta a estatística descritiva referente aos resultados dos 12 sujeitos com paralisia cerebral que não participaram da análise comparativa. Um destes não tem seus resultados representados aqui, pois seu severo comprometimento motor impediu uma avaliação neuropsicológica mínima com os testes usados pela presente pesquisa.

\section{Tabela 4}

\section{Estatística descritiva dos resultados no CANTAB não utilizados na análise de} comparação com os controles

\begin{tabular}{|c|c|c|c|c|c|}
\hline & n válido & Média & Mínimo & Máximo & Desvio Padrão \\
\hline PRM Média de latência para respostas corretas (ms) & 12 & 4872,267 & 2129,050 & 15095,83 & 3417,27 \\
\hline PRM Acertos (fase imediata) & 11 & 8,909 & 5,000 & 12,00 & 2,21 \\
\hline PRM Acertos (fase tardia) & 10 & 7,800 & 6,000 & 10,00 & 1,32 \\
\hline SRM Média de latência para respostas corretas (ms) & 11 & 4995,896 & 2099,500 & 19050,00 & 4803,23 \\
\hline SRM Acertos & 11 & 10,273 & 3,000 & 14,00 & 3,32 \\
\hline SSP Alcance (direto) & 10 & 3,400 & 2,000 & 5,00 & 1,07 \\
\hline SSP Erros (direto) & 10 & 10,500 & 4,000 & 25,00 & 5,99 \\
\hline SSP Erros de execução (direto) & 10 & 4,200 & 2,000 & 8,00 & 1,93 \\
\hline SSP Alcance (inverso) & 10 & 2,900 & 2,000 & 5,00 & 1,10 \\
\hline SSP Erros (inverso) & 10 & 8,600 & 6,000 & 15,00 & 2,80 \\
\hline SSP Erros de execução (inverso) & 10 & 2,100 & 0,000 & 5,00 & 1,79 \\
\hline SOC Resoluções com o mínimo de movimentos & 9 & 5,111 & 2,000 & 10,00 & 2,32 \\
\hline soC Tempo médio inicial de raciocínio (2) (ms) & 9 & 3673,278 & 0,000 & 11369,50 & 4320,69 \\
\hline SOC Média de movimentos (2) & 9 & 2,333 & 2,000 & 3,50 & 0,66 \\
\hline SOC Tempo médio subsequente de raciocínio (2) (ms) & 9 & 5542,611 & 0,000 & 24628,85 & 10563,83 \\
\hline SOC Tempo médio inicial de raciocínio (3) (ms) & 9 & 5571,000 & 1389,000 & 9151,50 & 2394,45 \\
\hline SOC Média de movimentos (3) & 9 & 4,167 & 3,000 & 6,00 & 1,15 \\
\hline SOC Tempo médio subsequente de raciocínio (3) (ms) & 9 & 8906,424 & 0,000 & 48693,66 & 15873,71 \\
\hline SOC Tempo médio inicial de raciocínio (4) (ms) & 9 & 4454,083 & 682,500 & 11485,25 & 3370,72 \\
\hline SOC Média de movimentos (4) & 9 & 6,139 & 4,250 & 8,00 & 1,31 \\
\hline SOC Tempo médio subsequente de raciocínio (4) (ms) & 9 & 6282,514 & 595,680 & 19873,76 & 6198,31 \\
\hline SOC Tempo médio inicial de raciocínio (5) (ms) & 9 & 3186,444 & 0,000 & 10516,50 & 3024,64 \\
\hline SOC Média de movimentos (5) & 9 & 8,667 & 5,250 & 12,00 & 2,24 \\
\hline SOC Tempo médio subsequente de raciocínio (5) (ms) & 9 & 3379,409 & 0,000 & 6683,04 & 2073,42 \\
\hline IED Erros em estágios completos & 9 & 16,222 & 5,000 & 28,00 & 7,66 \\
\hline IED Tentativas em estágios completos & 9 & 79,222 & 48,000 & 102,00 & 20,49 \\
\hline IED Erros ED & 9 & 15,556 & 0,000 & 26,00 & 9,51 \\
\hline IED Erros Pré-ED & 9 & 10,667 & 5,000 & 24,00 & 6,40 \\
\hline IED Estágios completos & 9 & 7,889 & 7,000 & 9,00 & 0,93 \\
\hline IED Erros & 9 & 32,333 & 19,000 & 48,00 & 9,37 \\
\hline IED Erros (ajustado) & 9 & 43,444 & 19,000 & 73,00 & 18,95 \\
\hline IED Tentativas & 9 & 112,556 & 82,000 & 152,00 & 25,31 \\
\hline IED Tentativas (ajustado) & 9 & 134,778 & 82,000 & 202,00 & 39,46 \\
\hline
\end{tabular}

Rev. Psicol Saúde e Debate. Dez., 2017:3(2):131-158. 
Tabela 4: Continuação

\begin{tabular}{lccccc}
\hline & n válido & Média & Mínimo & Máximo & Desvio Padrão \\
\hline & & & & & \\
CRT Latência máxima (tentativas corretas) (ms) & 10 & 2059,900 & 512,000 & 2936,00 & 898,86 \\
CRT Média de latência (tentativas corretas) (ms) & 10 & 808,740 & 323,350 & 1212,25 & 280,50 \\
CRT Latência mínima (tentativas corretas) (ms) & 10 & 303,000 & 196,000 & 433,00 & 78,05 \\
CRT Erros (antencipação) & 10 & 2,200 & 0,000 & 13,00 & 4,05 \\
CRT Tentativas corretas & 10 & 89,700 & 68,000 & 100,00 & 10,76 \\
CRT Tentativas incorretas & 10 & 6,600 & 0,000 & 20,00 & 6,15 \\
CRT Erros (omissão) & 10 & 1,500 & 0,000 & 8,00 & 2,55 \\
RVP A' & & & & & \\
RVP B" & 8 & 0,931 & 0,810 & 0,99 & 0,07 \\
RVP Latência média (ms) & 8 & 0,685 & 0,230 & 1,00 & 0,30 \\
RVP Probabilidade de alarme falso & 8 & 451,766 & 320,640 & 889,73 & 187,65 \\
RVP Probabilidade de acerto & 8 & 0,038 & 0,000 & 0,18 & 0,06 \\
RVP Rejeições corretas & 8 & 0,791 & 0,500 & 0,96 & 0,18 \\
RVP Alarmes falsos & 8 & 254,250 & 201,000 & 273,00 & 23,54 \\
RVP Acertos & 8 & 9,375 & 0,000 & 44,00 & 14,57 \\
RVP Erros & 8 & 19,000 & 12,000 & 23,00 & 4,34 \\
& 8 & 5,000 & 1,000 & 12,00 & 4,34 \\
\hline
\end{tabular}

Por fim, a tabela 5 representa as correlações encontradas no grupo das crianças com PC incluídas na análise comparativa do ANOVA entre idade, escolaridade e QI e os resultados obtidos no CANTAB.

Tabela 5

Correlações encontradas entre os resultados das crianças com PC no

CANTAB e suas idades, escolaridades e quocientes de inteligência.

\begin{tabular}{lcccccc}
\hline & & & & \multicolumn{3}{c}{ Valores de $\mathbf{p}$} \\
\cline { 5 - 7 } & Idade & Escolaridade & QI & Idade & Escolaridade & QI \\
\hline PRM Média de latência para respostas corretas (ms) & $-0,283$ & $-0,490$ & $-0,820^{\mathrm{a}}$ & 0,538 & 0,265 & $0,024^{\mathrm{a}}$ \\
PRM Acertos (fase imediata) & 0,423 & 0,522 & $-0,111$ & 0,345 & 0,229 & 0,812 \\
PRM Acertos (fase tardia) & 0,597 & 0,681 & 0,286 & 0,157 & 0,092 & 0,535 \\
& & & & & & \\
SRM Média de latência para respostas corretas (ms) & $-0,152$ & $-0,157$ & 0,609 & 0,745 & 0,737 & 0,147 \\
SRM Acertos & 0,608 & 0,560 & 0,683 & 0,148 & 0,191 & 0,091 \\
& & & & & & \\
SSP Alcance (direto) & $0,857^{\mathrm{a}}$ & 0,675 & $-0,013$ & $0,014^{\mathrm{a}}$ & 0,096 & 0,977 \\
SSP Erros (direto) & 0,512 & 0,487 & 0,495 & 0,240 & 0,268 & 0,259 \\
SSP Erros de execução (direto) & $-0,308$ & $-0,340$ & 0,286 & 0,502 & 0,455 & 0,535 \\
& & & & & & \\
SSP Alcance (inverso) & $0,806^{\mathrm{a}}$ & 0,648 & 0,271 & $0,029^{\mathrm{a}}$ & 0,115 & 0,557 \\
SSP Erros (inverso) & $0,902^{\mathrm{a}}$ & 0,746 & $-0,180$ & $0,005^{\mathrm{a}}$ & 0,054 & 0,699 \\
SSP Erros de execução (inverso) & 0,296 & 0,113 & $-0,236$ & 0,520 & 0,809 & 0,611 \\
\hline
\end{tabular}

Rev. Psicol Saúde e Debate. Dez., 2017:3(2):131-158. 


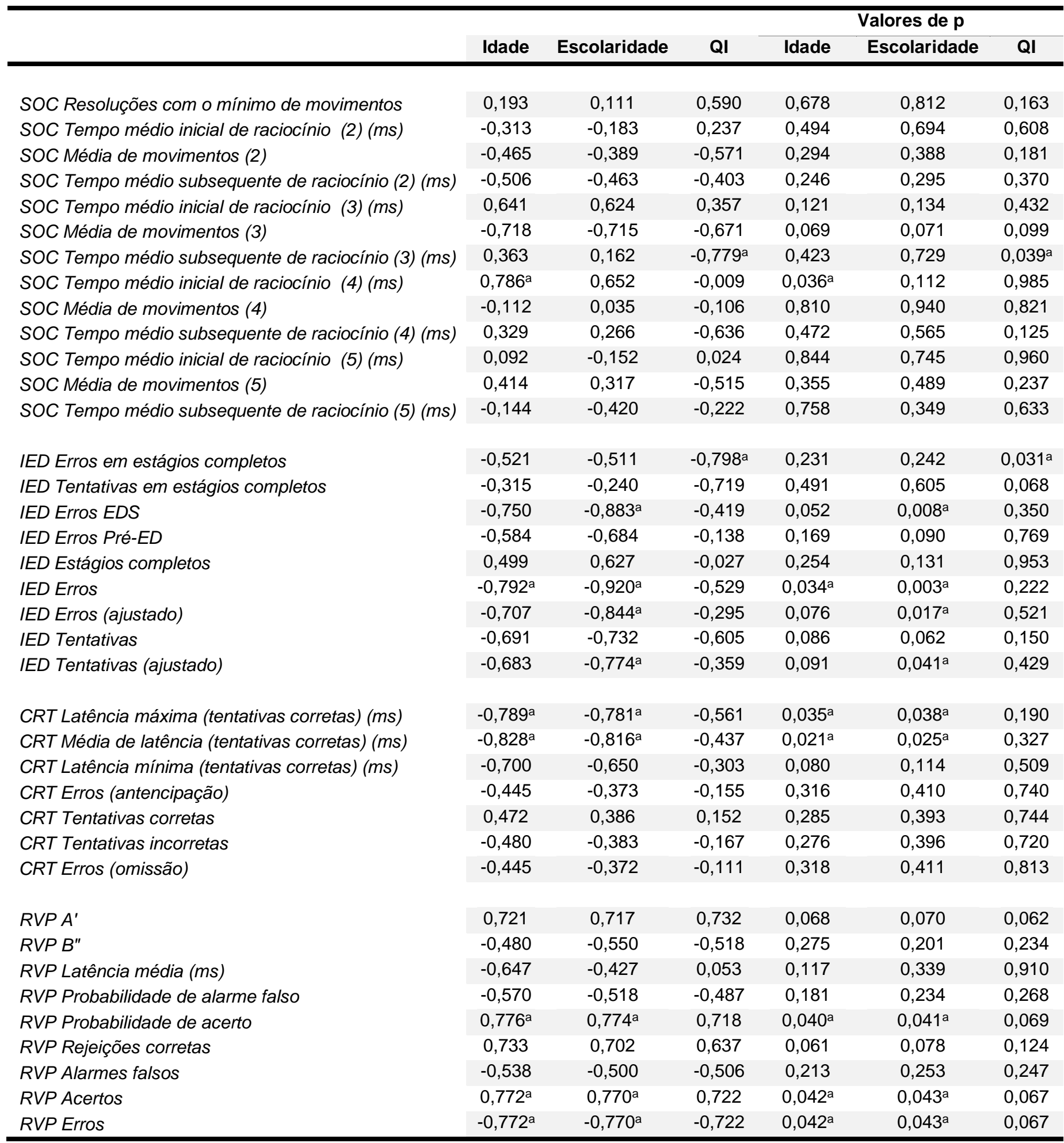

a'Os valores destacados indicam correlações significativas. As três colunas do lado direito contêm as significâncias $(p)$ de cada correlação, sendo destacados os valores de $p$ que correspondem às correlações significativas. 


\section{DISCUSSÃo}

A comparação dos resultados de ambos os grupos analisados no teste PRM indica um prejuízo no reconhecimento imediato de padrões visuais, o que pode ser associado a disfunções nas áreas temporais mediais do cérebro (Cambridge Cognition, 2005). Tal observação condiz com os resultados de um estudo (Carlsson, 1997) no qual se observaram prejuízos na memória de curto prazo relacionada a estímulos não-verbais (desenhos) em pacientes com paralisia cerebral hemiplégica resultante de lesões no hemisfério esquerdo. Esse desempenho contrasta com os dados que indicam preservação da memória de curto prazo para palavras. A partir disso o autor sugere que os comprometimentos observados para a recuperação de material não-verbal podem ser resultados de mecanismos compensatórios que propiciaram a reorganização dos mecanismos neurais responsáveis pela linguagem e, consequentemente, pela memória para conteúdo verbal, no hemisfério direito. Isso ocasionaria uma interferência (crowding) no processamento de estímulos não-verbais, inclusive no armazenamento destes, acarretando prejuízos de aquisição e recordação desse tipo de material (Carlsson, 1997). É possível que mecanismos de plasticidade neural como estes sugeridos pelo autor tenham interferido de maneira semelhante nos circuitos neurais dos indivíduos analisados pela presente pesquisa.

Todavia, outro estudo (Sabbadini et al., 2001) apontou o contrário, uma vez que a memória de curto prazo para estímulos não-verbais mostrou-se preservada em sujeitos com paralisia cerebral quadriplégica. Essa diferença de resultados é um indício de que se deve levar em conta a heterogeneidade inerente ao grupo de distúrbios englobado pelo termo "paralisia cerebral" e, adicionalmente, que para se considerar a aplicabilidade de tais resultados deve-se levar em conta a natureza específica da PC e das medidas utilizadas em cada pesquisa (Straub \& Obrzut, 2009).

Os resultados do CANTAB para memória operacional indicaram desempenhos comparáveis entre indivíduos com PC e controles. Uma pesquisa também apontou resultados semelhantes quanto à memória operacional para estímulos auditivos (White et al., 1994 apud Straub \& Obrzut, 2009). Esses resultados mostram a possível ação da plasticidade neural na infância, que poderia intervir de maneira a outras estruturas cerebrais compensarem os danos cognitivos ocasionados pelas lesões cerebrais em estruturas que originalmente contribuiriam para o funcionamento da memória operacional (Straub \& Obrzut, 2009). Esse processo pode influenciar não somente a circuitaria neural para estímulos auditivos como também para os estímulos visuo-espaciais presentes no teste SSP.

Rev. Psicol Saúde e Debate. Dez., 2017:3(2):131-158. 
Com relação às diferenças entre crianças com $\mathrm{PC}$ e controles quanto à latência de resposta no SRM, foi observada uma maior lentidão das respostas dos indivíduos do primeiro grupo. Uma explicação seria a dificuldade de movimentação dos membros superiores característica da paralisia cerebral, levando os sujeitos a responder mais lentamente do que os controles à tarefa exigida pelo teste. A igualdade estatística entre os resultados de ambos os grupos no restante das variáveis opõe-se aos achados da pesquisa de Lidzba e colaboradores (2006). Nesta, nos sujeitos com PC com lesões ocorridas nos períodos pré ou peri-natal, foram observados prejuízos em funções visuo-espaciais no teste Tube Figures, no qual o sujeito deveria adivinhar qual era a perspectiva de um objeto apresentada (visão da parte esquerda, ou da direita, por exemplo) (Lidzba et al., 2006).

O desempenho dos sujeitos de ambos os grupos no teste para avaliação de atenção sustentada (RVP) permite constatar a equivalência de desempenhos dessas duas amostras em todos os parâmetros dessa parte da bateria, incluindo o número de acertos, que indica quantas vezes o indivíduo respondeu à sequência correta de algarismos, e o número de rejeições corretas, que expõe quantas vezes o sujeito não respondeu às sequências numéricas incorretas. Tais resultados não condizem com aqueles encontrados na pesquisa de Bottcher e colaboradores (2009) que estudou a atenção sustentada como um dentre outros elementos que compõem a função neuropsicológica da atenção como um todo. Foi avaliado um total de 33 crianças, com paralisia cerebral espástica bi ou unilateral, cujo nível de inteligência se encontrava dentro de parâmetros de normalidade (Bottcher et al., 2009). Tal contradição de resultados pode ser avaliada criticamente de maneira semelhante àquela com a qual se procurou entender as diferenças de resultados em pesquisas que analisaram a memória de curto prazo. Desse modo, na pesquisa citada (Bottcher et al., 2009), é possível que os processos de reconfiguração funcional dos circuitos neurais responsáveis pela atenção sustentada não tenham tido o mesmo sucesso observado nos sujeitos analisados pelo presente estudo.

Essa contradição de resultados também foi observada nas medidas obtidas pelos testes CRT e SOC. O primeiro teste avalia o tempo de reação do sujeito diante de uma incerteza de orientação do estímulo. Para esse teste, não foram encontradas diferenças estatisticamente significativas em todos os parâmetros medidos. Um estudo já acima citado (Christ et al., 2003), entretanto, observou um desempenho inferior de sujeitos com paralisia cerebral quanto ao tempo de reação quando comparados com controles, sendo tal diferença ocasionada por prejuízos no controle inibitório das crianças com PC (Christ et al., 2003).

De igual maneira, não foram observadas discrepâncias significativas entre os desempenhos os dois grupos analisados no teste SOC, incluindo a quantidade de problemas 
resolvidos com o mínimo de movimentos possível, o número médio de movimentos dos sujeitos para cada tipo de problema, e os tempos médios iniciais e subsequentes para a resolução dos problemas. Tais resultados levam à conclusão de que para as crianças cujo desempenho é estudado, a função executiva de planejamento está preservada, sendo comparável àquela dos controles. Todavia, pesquisas apontam para a existência de prejuízos no domínio executivo, provavelmente ocasionados por danos nos tratos que carreiam informações de diversas áreas do encéfalo para o córtex pré-frontal (Straub \& Obrzut, 2009). Em uma delas (White \& Christ, 2005), modalidades de categorização (espontânea e auxiliada por pistas) de estímulos estavam prejudicas em indivíduos com PC. Outra pesquisa (Mutsaarts et al., 2006) indicou problemas no planejamento antecipatório numa tarefa de rotação de uma protuberância hexagonal na qual se devia prever as demandas perceptuais e motoras para que determinada meta fosse alcançada.

Os resultados, portanto, obtidos em alguns dos testes da bateria neuropsicológica aqui utilizada, levam a contradições quanto às conclusões de outras pesquisas que abordaram aspectos semelhantes (planejamento, atenção sustentada, tempo de reação e memória visuo-espacial e visual de curto prazo). No entanto, como primeiramente fora visto para as diferenças entre as medições de memória visual de curto prazo em diferentes estudos, deve-se entender esses resultados dentro dos aspectos de grande variabilidade inerentes à paralisia cerebral bem como nos métodos através dos quais se avalia o funcionamento neuropsicológico dos indivíduos afetados por essa disfunção primariamente motora (Straub \& Obrzut, 2009). Nesse sentido, as diferenças podem surgir em vista da interação entre os processos de plasticidade neural e as condições ambientais e do organismo da criança, particularmente, as configurações das lesões cerebrais e o momento em que estas ocorreram.

Comparações podem ser estabelecidas, por exemplo, ao se observar o comprometimento motor dos sujeitos cujos desempenhos foram avaliados nas pesquisas. Isso só é possível ao se tomar como base a noção de que o funcionamento motor na paralisia cerebral pode estar mais prejudicado, ou menos, dependendo da extensão da lesão cerebral (Straub \& Obrzut, 2009). Desse modo, o grau do comprometimento motor, dentro do âmbito das funções motoras gerais, pode ser usado como um modo de prever quão prejudicado está o funcionamento cognitivo do paciente (Himmelman et al.,2006).

Tal previsibilidade possui uma justificativa biológica dentro das limitações dos processos de plasticidade neural. Os primeiros pesquisadores do campo da neuropsicologia infantil acreditavam num grande potencial plástico do cérebro de uma criança mesmo diante de perdas consideráveis, como ocorre em uma hemisferectomia para tratamentos de epilepsia (Thomas, 2003). Todavia, outra visão considera essa ideia excessivamente otimista, 
considerando que a mesma relação entre o prejuízo funcional e a configuração da lesão observada em adultos também se mantém no caso de crianças (Thomas, 2003). Assim, temse que quanto mais severa for a lesão, maior será o prejuízo neuropsicológico.

Uma forma de conciliar tais ideias seria considerar a natureza e a severidade da lesão, assim como a ocasião em que esta surge (Thomas, 2003). De maneira geral, a plasticidade está relacionada com insultos cerebrais focais. Assim, lesões focais pequenas estão relacionadas com uma boa recuperação neuropsicológica. Por outro lado, lesões focais maiores também permitem um bom restabelecimento desde que sejam unilaterais, admitindo uma transferência de funções entre os hemisférios, ainda que resultem em crowding semelhante ao observado na interação entre memórias de curto prazo verbal e não-verbal. Para lesões bilaterais, a plasticidade não é tão evidente, geralmente acarretando em resultados pouco apreciáveis. Por último, lesões generalizadas ou difusas raramente permitem uma boa recuperação, resultado da baixa influência dos processos de plasticidade nesses casos (Thomas, 2003).

Os efeitos neuropsicológicos das lesões também variam de acordo com o momento em que surgem as lesões (Thomas, 2003). Assim sugere-se que, no período pré-natal, os danos cerebrais resultam em péssimas recuperações, com nenhuma evidência de funções realocadas dos tecidos lesionados para os tecidos preservados (Thomas, 2003). No início da infância, por outro lado, o restabelecimento é mais evidente, com maior preservação das funções resultante de uma reestruturação cerebral anormal (Thomas, 2003). Aproximando-se do final da adolescência e na idade adulta, a plasticidade torna-se progressivamente menos eficiente, como os diversos quadros clínicos evidenciam (Thomas, 2003).

Esses dois fatores (configuração da lesão e ocasião em que ela surge) combinados auxiliam a compreender as contradições de resultados nas pesquisas que têm como alvo a neuropsicologia da paralisia cerebral. O estudo que analisou o tempo de reação (Christ et al., 2003), por exemplo, teve como sujeitos participantes 13 crianças com paralisia cerebral bilateral, sendo 11 destas pacientes ambulatoriais, e as duas restantes necessitando máxima assistência para dar alguns passos. A pesquisa de White \& Christ (2005) analisou aspectos de funções executivas utilizando sujeitos em situações semelhantes às do estudo anterior, ou ainda o estudo de Bottcher e colaboradores (2009), no qual foi avaliada a atenção sustentada de sujeitos com PC ocasionada por danos ocorridos intrauterinamente. Esses exemplos podem ilustrar como as discrepâncias de resultados no âmbito cognitivo surgem a partir dos diferentes graus de severidade dos prejuízos motores bem como da origem temporal do distúrbio. 
Desse modo, pode-se concluir a respeito dos resultados da presente análise e da comparação desta com outros estudos que a pesquisa com o foco na paralisia cerebral deve considerar os métodos, incluindo a escolha dos testes e dos sujeitos, para entender a aplicabilidade das informações obtidas.

Os dados obtidos com as avaliações do CANTAB neste estudo indicam a possibilidade de que crianças com paralisia cerebral tenham muitos domínios neuropsicológicos preservados, evidenciado pelo desempenho comparável com os resultados do grupo controle. Observações semelhantes já foram feitas por Tabaquim (2002) em pacientes hemiparéticos, que apresentaram resultados semelhantes àqueles de indivíduos não-lesionados em todos os instrumentos utilizados, inclusive WISC e o Teste das Matrizes Progressivas de Raven. A autora sugere que a criação de novas conexões neurais proporcionou o restabelecimento das funções até o nível de normalidade (Tabaquim, 2002).

Todavia, não é possível um maior aprofundamento somente com os dados obtidos na presente pesquisa. Estudos futuros com o CANTAB deverão obter uma amostra maior, além de incluir não somente dados de escolaridade e QI, mas também informações neuropatológicas: quando o insulto ocorreu e a configuração deste a partir de exames de imageamento cerebral (localização e extensão). Assim, será possível estabelecer correlações mais precisas entre os processos de plasticidade neural e o funcionamento cognitivo e comportamental da criança, o que auxilia na superação do obstáculo da variabilidade constituinte da paralisia cerebral.

\section{AGRADECIMENTOS}

Os autores agradecem ao Curso de Fisioterapia da Universidade de São Paulo pelo envio dos pacientes; Jaelsa Cunha Pereira pela avaliação e classificação motora dos pacientes. Esta pesquisa foi realizada com suporte da Fundação de Amparo à Pesquisa do Estado de São Paulo - FAPESP (Projeto Temático 02/12733-8) e Conselho Nacional de Desenvolvimento Científico e Tecnológico - CNPq (Projeto \#523303/95-5). 


\section{REFERÊNCIAS}

Angelini, A. L., Alves, I. C. B., Custódio, E. M., Duarte, W. F., \& Duarte, J. L. M. (1999). Manual. Matrizes progressivas coloridas de Raven: escala especial. São Paulo: Centro Editor de Testes e Pesquisas em Psicologia.

Bax, M., Tydeman, C., \& Flodmark, O. (2006). Clinical and MRI correlates pf cerebral palsy. Journal of the American Medical Association, 296 (13), 1602-1608.

Bottcher, L., Flachs, E. M., \& Uldall, P. (2009). Attentional and executive impairments in children with spastic cerebral palsy. Developmental Medicine \& Child Neurology, 52, 42-47.

Cândido, A. M. D. M. (2004). Paralisia Cerebral: Abordagem para o pediatra geral e manejo multidisciplinar. Monografia, Curso de Residência Médica em Pediatria, Hospital Regional da Asa Sul, Brasília, DF.

Cambridge Cognition (2005). CANTABeclipse. Test Administration Guide / Manual version 2.0.0. Cambridge: Cambridge Cognition Limited.

Christ, S. E., White, D. A., Brunstrom, J. E., \& Abrams, R. A. (2003) Inhibitory control following perinatal brain injury. Neuropsychology, 17 (1), 171-178.

Costa, D. I., Azambuja, L. S., Portuguez, M. W., \& Costa, J. C. (2004). Avaliação neuropsicológica da criança. Jornal de Pediatria 80(2) (supl.) 111-116.

Campos, F. (2004). Teste das Matrizes Progressivas: Escala geral séries A, B, C, D e E. Manual. Rio de Janeiro: CEPA.

Carlsson, G. (1997). Memory for words and drawings in children with hemiplegic cerebral palsy. Scandinavian Journal of Psychology, 38, 265-273.

Courbois, Y., Coello, Y., \& Bouchard, I. (2004). Mental imagery abilities in adolescents with spastic diplegia cerebral palsy. Journal of Intellectual \& Developmental Disability, 29 (3), 226338.

Dahlgren-Sandberg, A. (2006). Reading and spelling abilities in children with severe speech impairments and cerebral palsy at 6,9 , and 12 years of age in relation to cognitive development: A longitudinal study. Developmental Medicine and Child Neurology, 48, 629634.

Fedrizzi, E., Inverno, M., Bruzzone, M. G., Botteon, G., Saletti, V., \& Farinotti, M. (1996). MRI features of cerebral lesions and cognitive functions in preterm spastic diplegic children. Pediatric Neurology, 15 (3), 207-212.

Himmelmann, K., Beckung, E., Hagberg, G., \& Uvebrant, P. (2006). Gross and fine motor function and accompanying impairments in cerebral palsy. Developmental Medicine and Child Neurology, 48, 417-423. 
Lidzba, K., Staudt, M., Wilke, M., \& Krägeloh-Mann, I. (2006). Visuospatial deficits in patients with early left-hemispheric lesions and functional reorganization of language: Consequence of lesion or reorganization? Neuropsychologia, 44, 1088-1094.

Mutsaarts, M., Steenbergen, B., \& Bekkering, H. (2006). Anticipatory planning deficits and task context effects in hemiparetic cerebral palsy. Experimental Brain Research, 172 (2), 151-162.

Pirila, S., van der Meere, J., Pentikainen, T., Ruusu-Niemi, P., Korpela, R., \& Kilpinen, J. (2007). Language and motor speech skills in children with cerebral palsy. Journal of Communication Disorders, 40, 116-128.

Sabbadini, M., Bonanni, R., Carlesimo, G. A., \& Caltagirone, C. (2001). Neuropsychological assessment of patients with severe neuromotor and verbal disabilities. Journal of Intellectual Disability Research, 45, 160-179.

Schatz, J., Craft, S., Koby, M., \& Park, T. S. (1997). Associative learning in children with perinatal brain injury. Journal of the International Neuropsychological Society, 3, 521-527.

Spreen, O., Strauss, E., \& Sherman, E. M. S. (2006). A Compendium of Neuropsychological Tests ( $3^{\circ}$. ed.). Nova lorque, Oxford University Press.

Straub, K. \& Obrzut, J. E. (2009). Effects of Cerebral Palsy on Neuropsychological Functions. Journal of Developmental and Physical Disabilities, 21(2), 153-167.

Tabaquim, M. L. M. (2002). Avaliação neuropsicológica: estudo comparativo de crianças com paralisia cerebral hemiparética e distúrbios de aprendizagem. Dissertação de Doutorado, Universidade de Campinas, Faculdade de Ciências Médicas, Campinas.

Thomas, M. S. C. (2003). Limits on plasticity. Journal of Cognition and Development, 4(1), 95121.

Wann, J. P. (1991). The integrity of visual-proprioceptive mapping in cerebral palsy. Neuropsychologia, 29 (11), 1095-1106.

White, D. A., \& Christ, S. (2005). Executive control of learning and memory in children with bilateral spastic cerebral palsy. Journal of the International Neuropsychological Society, 11, 920-924 